\title{
Microgeographic variation in rDNA intergenic spacers of Anopheles gambiae in western Kenya
}

\author{
Denson Kelly McLain, ${ }^{*}$ \\ Frank H. Collins, * \\ A. David Brandling-Bennett* $\dagger$ and \\ J. B. O. Were $\dagger$
}

\begin{abstract}
* Malaria Branch, Division of Parasitic Diseases, Center for Infectious Diseases, Centers for Disease Control, Public Health Service-U.S. Department of Health and Human Services, Atlanta, Georgia 30333, U.S.A.

$\uparrow$ Clinical Research Centre, Kenya Medical Research Institute, Nairobi, Kenya.
\end{abstract}

The genetic population structure of Anopheles gambiae (Diptera: Culicidae) in western Kenya was investigated by hybridizing a rapidly evolving rDNA intergenic spacer sequence to restriction endonuclease digests of genomic DNA extracted from single mosquitoes from seven localities. Significantly different distributions of restriction fragment arrays were obtained from field sites less than $10 \mathrm{~km}$ apart, which suggests restricted gene flow and a subdivided population structure. Eight of twenty-one possible comparisons between pairs of populations yielded significant differences. An eastern Kenya coastal population did not share its restriction fragment arrays with any of the western populations, suggesting that isolation by distance can be complete on a relatively small geographic scale (700 km).

\section{MICROGEOGRAPHIC VARIATION IN RDNA INTERGENIC SPACERS OF ANOPHELES GAMBIAE IN WESTERN KENYA}

Population structure is the spatial relationship on a micro- or macrogeographic scale between genetically differentiated demes; it is a consequence of gene flow rates (Wright, 1940 and 1943) and environmental heterogeneity (Hedrick et al., 1976; Hoffman and Neilson, 1985). Population structure influences the potential for adaptation to spatially varying selection pressures (Roughgarden, 1979), the importance of drift in accelerating interpopulation divergence (Wright, 1978), and the level at which selection acts (Wilson, 1980 and 1987; Nunney, 1985; Wade and McCauley, 1984).

The present study examines the genetic structure of Anopheles gambiae Giles mosquito populations representing seven localities in western Kenya. Genetic structure is investigated through the analysis of restriction fragment length polymorphism in the intergenic spacer (IGS) of rDNA through the hybridization of cloned spacer sequences to restriction digests of individual mosquitoes.

$\ddagger$ Present address: Department of Biology, Landrum Box 8042, Georgia Southern College, Statesboro, Georgia 30460, U.S.A.
Two lines of evidence suggest that the IGS evolves rapidly in $A$. gambiae: sibling species are divergent in their IGS (McLain and Collins, in press) suggesting rapid concerted evolution (Dover, 1982), and laboratory colonies established from geographically isolated populations of $A$. gambiae vary in the sequence or structure of the IGS.

A. gambiae is widespread across Africa south of the Sahara but is restricted in its reproduction to periods of seasonal rain (Coluzzi et al., 1977). Local populations are succeptible to changing ecological conditions (Chenery, 1984) and may display ecotypic divergence (e.g., savanna versus forest types) associated with chromosomal inversions (Coluzzi et al., 1985). Divergence associated with habitat that may or may not reflect local adaptation suggests subdivided population structure. A. gambia is the principal vector of the malaria parasite, Plasmodium falciparum, in Africa (Service, 1982 and 1985). The World Health Organization estimates that there are approximately 100 million clinical cases of malaria each year and that 1 per cent of these are terminal (WHO, 1985). Thus, studies of population structure are of importance in assessing not only evolutionary dynamics but also the potential of the mosquito to disperse drugresistant strains of $P$. falciparum. 


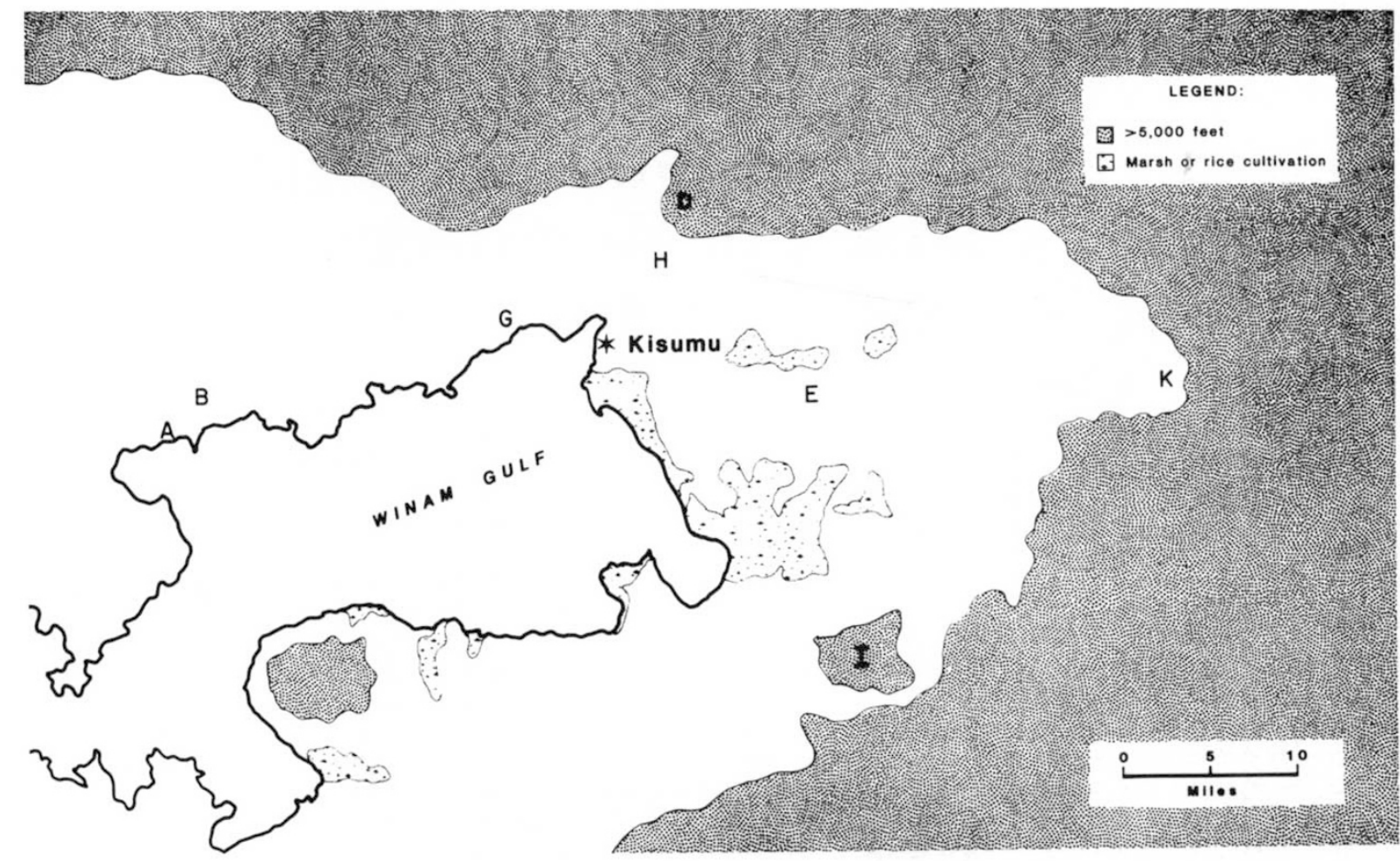

Figure 1 Distribution of villages (collecting sites) around Kisumu in western Kenya. Village names: A, Asembo Bay; B, Bama Creek; D, escarpment above Wathrego; E, Ahero; G, Kisian; H, Wathrego; I, Nyakoch; K, Muhroni. Not shown: J, Jego (near Mombasa, coastal Kenya).

\section{METHODS}

\section{Collection sites}

Figure 1 gives the distribution of mosquito collection sites around Kisumu in western Kenya. Mosquitoes were also collected from site $\mathrm{J}$ on the eastern coast of Kenya. Except for site E, Ahero, where only A. arabiensis was collected, A. gambiae and $A$. arabiensis were both present in collections. A. arabiensis is one of six recognized sibling species in the $A$. gambiae complex. Collections were made in May, 1987.

Resting females were collected during daylight hours by aspiration from the mud walls of sleeping and cooking quarters. Gravid females were etherized lightly and sequestered singly into cottonplugged, oviposition vials containing water and moistened filter paper. Once eggs were laid, they were collected onto the filter paper which was then dried by exposure to open air for two hours. Dried eggs were hatched in three days and reared to adulthood at which point DNA was extracted. For each site, DNA was extracted from a single, ran- domly chosen female offspring of 20 different fieldcollected females. Since $A$. gambiae and $A$. arabiensis are morphologically indistinguishable some of the blots which follow contain $A$. arabiensis as well as A. gambiae. These species are, however, easily differentiated by their rDNA hybridization profiles (Collins et al., 1987).

\section{Genetic analyses}

DNA was extracted from single mosquitoes by the procedure of Livak (1984) but with all volumes doubled. All of the DNA extracted from one individual was cleaved in a single volume of $40 \mu \mathrm{l}$ containing 40 units of the restriction endonuclease Xho I (Bethesda Research Laboratories, Gaithersburg, MD: use of trade names is for identification only and does not constitute endorsement by the Public Health Service or the U.S. Department of Health and Human Services). Digestions proceeded overnight for $12-16$ hours at $37^{\circ} \mathrm{C}$.

Cleaved DNA was fractionated by size on 0.75 per cent agarose gels and transferred to gene screen 


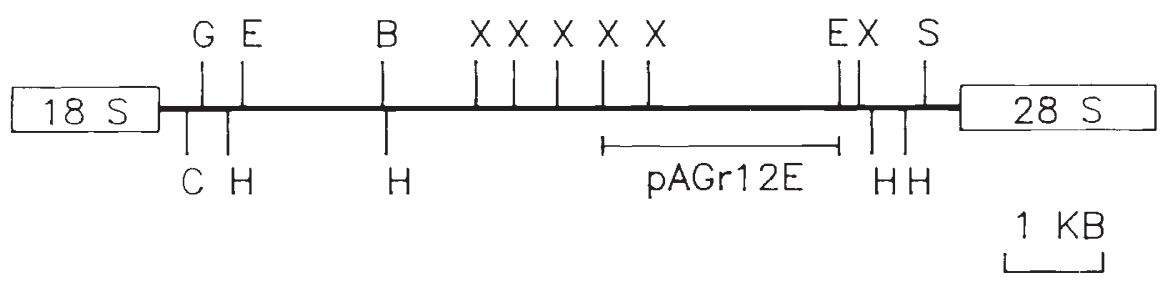

Figure 2 Restriction map of rDNA intergenic spacer of the $A$. gambiae clone from which the probe, pAGr12E, was obtained. The region of the spacer encompassed by the probe is also indicated. Restriction sites: $B=\mathrm{BamHI}, \mathrm{C}=\mathrm{SacII}, \mathrm{E}=\mathrm{EcoRI}, \mathrm{G}=\mathrm{Bgl} \mathrm{II}$, $\mathrm{H}=$ Hind III, $\mathrm{S}=\mathrm{Sal} \mathrm{I}$, and $\mathrm{X}=\mathrm{X}$ ho $\mathrm{I}$.

membrane (NEN Research Products, Boston, MA) by the Southern (1975) blotting procedure. Hybridization of radio-labelled probe to membrane bound DNA was conducted under stringent conditions (50 per cent formamide, 6X SSC at $42^{\circ} \mathrm{C}$; Maniatis et al., 1982; Strachan et al., 1982). Filters were washed three times for 45 minutes each at $50^{\circ} \mathrm{C}$ in $0 \cdot 1$ per cent SDS $2 \times \mathrm{SSC}$.

Two different probes were sequentially used on each filter (fig. 2). The subcloning of these probes is described in McLain and Collins (1989). The probe pAGr12E contains sequences in the middle of the intergenic spacer. This probe gives one or more bands of $>9 \mathrm{~kb}$ (kilobases) for Xho I digests of $A$. arabiensis DNA and one or more bands of $<2 \mathrm{~kb}$ for Xho I digests of $A$. gambiae DNA (McLain and Collins, 1989). This probe was also used to show microgeographic variation in the IGS of rDNA repeats. Old probe was stripped from filters prior to reprobing with the other subclone. This entailed soaking the filter with gentle agitation for 30 minutes at $42^{\circ} \mathrm{C}$ in $0.4 \mathrm{M} \mathrm{NaOH}$. Stripped filters were neutralized in $0 \cdot 1 \mathrm{M}$ trizma base, $0 \cdot 1 \mathrm{X} \mathrm{SSC}, 0 \cdot 1$ per cent $\operatorname{SDS}(p \mathrm{H} 7 \cdot 5)$ for 30 minutes at $42^{\circ} \mathrm{C}$.

The completeness of restriction endonuclease digestion was confirmed for each filter by stripping and reprobing with the internal transcribed spacer subclone pAGr12C (McLain and Collins, 1989). This probe gives a single band of hybridization for Xho I digests of all A. gambiae complex species.

Observed variation within the rDNA intergenic spacer may represent length variation arising from varying numbers of subrepeats or from the gain/loss of restriction sites. Intragenomic variation may also reflect the distinctive characteristics of different NOR's. Since these different sources of variation are not identified and characterized in the present study, the variable hybridization profiles observed are referred to as rDNA array types.

\section{Statistics}

The statistical significance of differences in rDNA array type distributions in populations is tested with $R \times C$ tests of independence (Sokal and Rohlf, 1981). This test utilizes a $G$-statistic to address the null hypothesis that frequency distributions of rDNA array types do not differ between populations. Since there were seven populations in western Kenya, $R$ is seven while $C$ is two, four or seven depending on the total number of rDNA array types recognized. The test statistic, $G$, is calculated as follows: $G=2\left[\left(\sum f \ln f\right.\right.$ for cell frequencies $)-\left(\sum f \ln f\right.$ for row and column totals) $+n \ln n]$. The cell frequency from the $R \times C$ matrix is $f$ and total sample size is $n$. To determine the microgeographic scale of population structure it is necessary to make pairwise comparisons between population array type frequencies. The test of independence using the $G$-statistic is again employed. The calculation of $G$ is as described above. For both tests, the value of $G$ is compared with a Chi-square distribution with $(R-1)(C-1)$ degrees of freedom (Sokal and Rohlf, 1981).

\section{RESULTS}

Variability in the rDNA IGS of $A$. gambiae in western Kenya is revealed by the presence/absence of eight different bands of hybridization to the IGS sequence in the subclone pAGr12E (figs 3 and 4). Hybridization to Xho I-bounded sequences of 2000 base pairs (bp) and $400 \mathrm{bp}$ was observed in all individuals from all populations. The other six fragments were variable in their distribution between mosquitoes within and between populations. However, the presence or absence of hybridization to two of these variable fragments, those of $500 \mathrm{bp}$ and $300 \mathrm{bp}$, was difficult to ascertain for some individuals, so these fragments are 


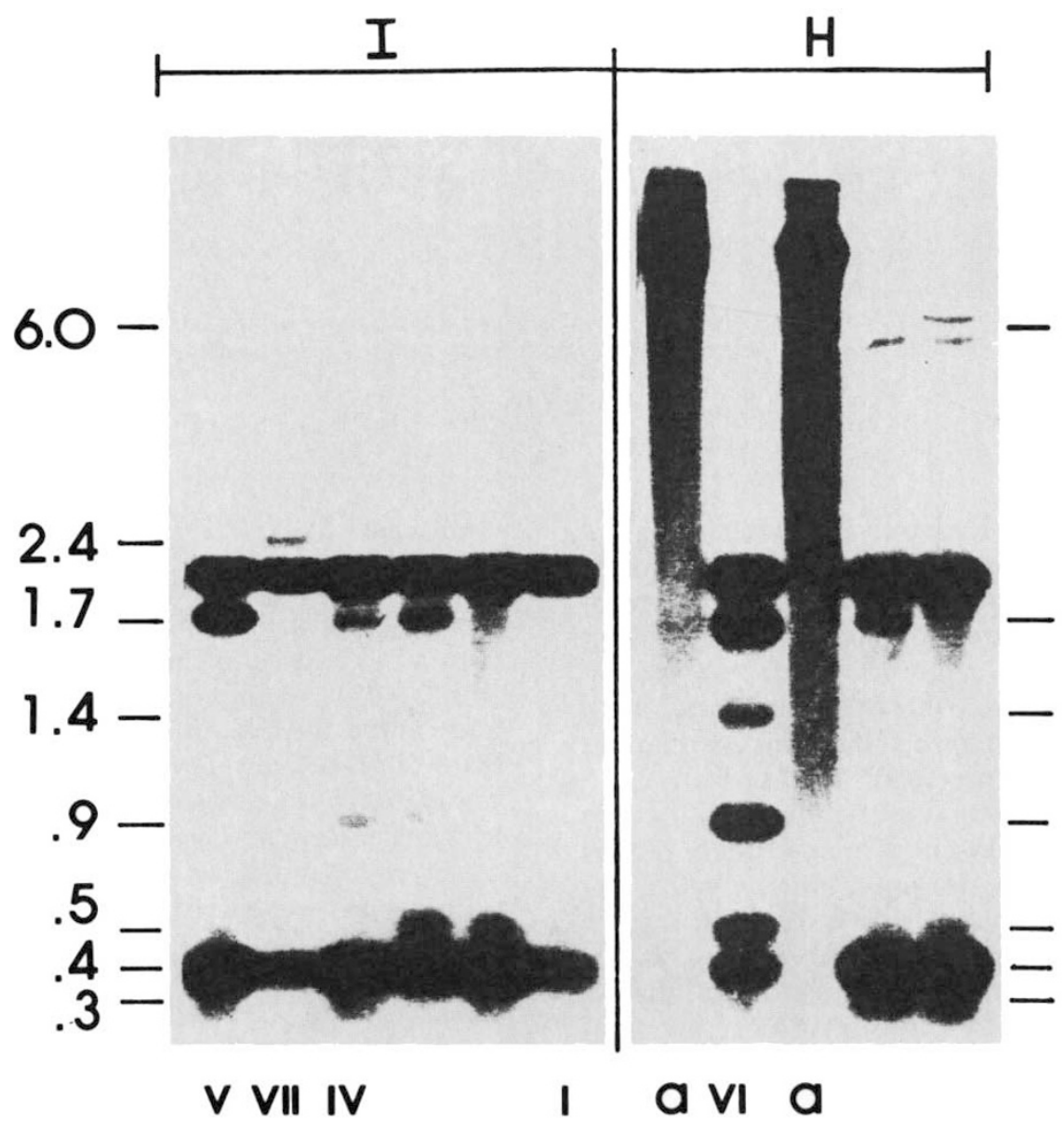

Figure 3 Representative rDNA array types of mosquitoes from sites I and $\mathrm{H}$ when probed with pAGr12E, containing intergenic spacer sequences. Numbers beside lanes are lengths (kilobases) of Xho I-bounded fragments. Lanes with $A$. arabiensis are indicted by an "a" beneath the blot; all other lanes contain A. gambiae. Numerals beneath lanes correspond to rDNA array types in table 1 . Array types are not specified for lanes with faintly photographing fragments.

ignored in the analyses that follow. The remaining variable bands of hybridization are to Xho Ibounded sequences of $2400 \mathrm{bp}, 1700 \mathrm{bp}, 1400 \mathrm{bp}$, and $900 \mathrm{bp}$.

Including individuals with none of the variable restriction fragments, there are 16 different genotypes possible based only on the presence or absence (not abundance) of different variable fragments of 900-2400 bp length. Seven of these were observed in western Kenya (table 1). Three of these (1. $1700 \mathrm{bp}+1400 \mathrm{bp}+900 \mathrm{bp} ; 2.1700 \mathrm{bp}$; and 3 . no variable sequences present) account for 77 per cent of the individuals observed.

The seven populations in western Kenya averaged $5 \cdot 0(\mathrm{SD}=1 \cdot 6)$ different rDNA array types among the 20 mosquitoes sampled from each. No two populations had completely different sets of rDNA array types. Therefore, genetic structure must be recognized in differences in the frequencies of shared rDNA array types. There was a

Table 1 Frequency of seven rDNA array types in seven populations of $A$. gambiae in western Kenya. Numbers at column head are sizes (bp) of variable restriction fragments

\begin{tabular}{lccccccc}
\hline $\begin{array}{l}\text { rDNA } \\
\text { array type }\end{array}$ & I & II & III & IV & V & VI & VII \\
\hline \multicolumn{1}{l}{} & & & & & & 1700 & \\
Site & None & 900 & 1400 & 900 & 1700 & 900 & 2400 \\
\hline A & 4 & 1 & 1 & 1 & 11 & 2 & 0 \\
B & 7 & 5 & 1 & 1 & 1 & 5 & 0 \\
D & 14 & 2 & 0 & 0 & 2 & 2 & 0 \\
G & 0 & 0 & 0 & 0 & 8 & 12 & 0 \\
H & 7 & 3 & 0 & 2 & 5 & 3 & 0 \\
I & 5 & 7 & 1 & 1 & 2 & 3 & 1 \\
K & 2 & 2 & 0 & 1 & 0 & 13 & 2 \\
\hline
\end{tabular}




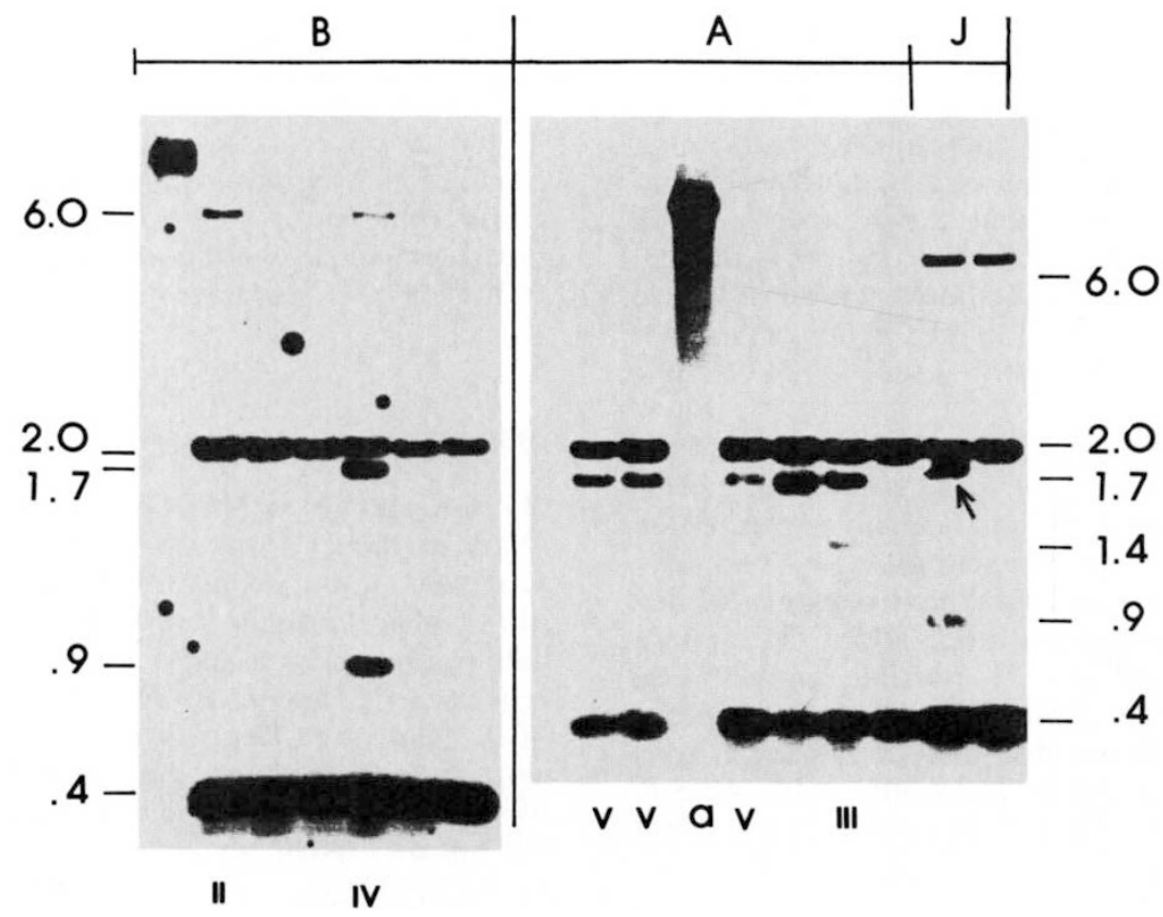

Figure 4 Representative rDNA array types of mosquitoes from sites B, A and J when probed with pAGr $12 \mathrm{E}$, containing intergenic spacer sequences. Numbers beside lanes are lengths (kilobases) of Xho I-bounded fragments. Lane with $A$. arabiensis is indicated by an "a" beneath the blot; all other lanes contain $A$. gambiae. Numerals beneath lanes correspond to rDNA array types in table 1 . The arrow points to the $1.8-1.9 \mathrm{~kb}$ fragment observed only in mosquitoes from site $J$. Array types are not specified for lanes with faintly photographing fragments.

significant difference between the seven western populations in the frequency distributions of the seven $\mathrm{rDNA}$ array types $(G=103.2, \mathrm{df}=36, P<$ $0 \cdot 001)$.

For pair-wise analyses, three rDNA array types and one composite of the remaining four were recognized instead of all seven since this reduces the degrees of freedom from six to three, concomitantly reducing the value of $G$ necessary for statistical significance (for $G>7.81, P<0.05$ ). This approach was adopted since the sample size was small ( $n=20$ mosquitoes per population). The fol- lowing rDNA array types were recognized: (1) no variable fragments present, (2) only the $1700 \mathrm{bp}$ fragment present, (3) three variable fragments present (1700 bp, $1400 \mathrm{bp}$, and $900 \mathrm{bp}$ ), and (4) all other rDNA array types (Types II, III, IV and VII of table 1).

The results of the statistical analysis of differences between all possible pairs of populations were tabulated (table 2). Of the 21 combinations, eight were significantly different $(P<0 \cdot 05)$ while an additional comparison was marginally significant $(0 \cdot 05<P<0 \cdot 10)$. The distribution of rDNA array

Table 2 Values of $G$ for comparisons between populations in the distribution of four rDNA array types among 20 individuals sampled from each

\begin{tabular}{llllllc}
\hline & \multicolumn{2}{l}{ Population } & & & \\
\cline { 2 - 6 } Population & B & D & G & H & I & K \\
\hline A & 4.76 & 5.09 & $8 \cdot 46^{* *}$ & 1.07 & $3 \cdot 80$ & $10 \cdot 01^{* *}$ \\
B & - & 2.57 & $14 \cdot 29^{* *}$ & 1.93 & $0 \cdot 87$ & $4 \cdot 18$ \\
D & - & - & $16.98^{* *}$ & 1.99 & 3.94 & $10 \cdot 66^{* *}$ \\
G & - & - & - & $10 \cdot 07^{* *}$ & $15 \cdot 22^{* *}$ & $10 \cdot 42^{* *}$ \\
H & - & - & - & - & $2 \cdot 24$ & $7 \cdot 51^{*}$ \\
I & - & - & - & - & - & $6 \cdot 28^{*}$ \\
\hline
\end{tabular}

** For $P<0.05$. ${ }^{*}$ For $0.05<P<0 \cdot 10$. 
types at site $\mathrm{G}$ was significantly different from all others while the distribution at site $\mathrm{K}$ was significantly different from that at three of the six other sites (table 2). In addition, the distribution at site $\mathrm{K}$ was marginally significantly different $(0.05<P<0.10)$ from that at two other sites. An $R \times C$ test of independence rejects the null hypothesis that the populations in western Kenya do not differ with regard to the frequency distribution of the four rDNA array types $(G=88.88, \mathrm{df}=$ $18, P<0.001$ ).

Similar significant differences in frequency distribution are obtained if the presence/absence of only the variable $1700 \mathrm{bp}$ fragment is considered for the seven western populations $(G=48 \cdot 06, \mathrm{df}=$ $6, P<0.001$ ). Table 3 gives the frequency of this fragment in the seven populations in western Kenya. Eight of the 21 possible comparisons between different populations yielded significant differences while an additional three comparisons gave marginally significant results (table 4). Site A now differs significantly from sites D and I, but not from site $\mathrm{K}$.

Table 3 Frequency of rDNA array types with and without the 1700 bp variable fragment in seven populations in western Kenya

\begin{tabular}{rrrrrrrr}
\hline & \multicolumn{3}{l}{ Population } & & & & \\
\cline { 2 - 7 } & A & B & D & G & H & I & K \\
\hline Present & 15 & 7 & 4 & 20 & 10 & 6 & 14 \\
Absent & 5 & 13 & 16 & 0 & 10 & 14 & 6
\end{tabular}

The population from coastal Kenya (site $\mathrm{J}$ ) had two rDNA array types relative to probing with the IGS subclone, neither of which was present in any of the populations from western Kenya (fig. 4). These rDNA array types were characterized by sequences of $6000 \mathrm{bp}, 2000 \mathrm{bp}, 900 \mathrm{bp}$ and $400 \mathrm{bp}$ $(n=14)$ or sequences of $6000 \mathrm{bp}, 2000 \mathrm{bp}, 1800$ $1900 \mathrm{bp}$, and $400 \mathrm{bp}(n=6)$. Thus, the only variable fragment at site $J$ was the $1800-1900$ bp sequence. Populations in western Kenya also give hybridization to bands around $6000 \mathrm{bp}$ in length but the hybridization is weak and variable. The coastal population hybridizes much more strongly and consistently to the $6000 \mathrm{bp}$ fragment. The size of this fragment does not correspond exactly in size to the variable bands around $6000 \mathrm{bp}$ in western Kenya.

\section{DISCUSSION}

Hybridization of rDNA IGS sequences to genomic DNA extracted from single mosquitoes reveals spacer variation within those mosquitoes. Some of this may represent IGS length variation generated by unequal crossing-over between spacer subrepeats (e.g., Tautz et al., 1987). Some populations of A. gambiae in Kenya have fewer rDNA spacer array types than others. For example, 70 per cent of the mosquitoes from site $D$ have none of the $900 \mathrm{bp}$, or $1700 \mathrm{bp}$ sequences while 100 per cent of the mosquitoes from site $G$ have one or more of these. Populations with less variable spacer arrays may be relatively more homogenized with regard to specific spacer sequence variants as a consequence of unequal crossing-over or gene conversion (Strachan et al., 1982; Coen and Dover, 1983).

However, it is difficult to ascribe variation in the size of hybridizing restriction fragments to the gain/loss of restriction sites or, alternatively, to length variation generated by unequal crossingover between subrepeats. Restriction site variants could be homogenized but simple length variants will be continually regenerated. Other studies of natural populations have revealed varying degrees of homogenization of sequence variants of multigene families (Coen et al., 1982; Strachan et al., 1985; Learn and Schaal, 1987). In the present study, spacer restriction fragments of $400 \mathrm{bp}$ and

Table 4 Values of $G$ for comparisons between populations on the abundance of rDNA array types with and without the $1700 \mathrm{bp}$ variable fragment

\begin{tabular}{lllllll}
\hline & \multicolumn{2}{l}{ Population } & & & & \\
Population & B & D & G & H & I & K \\
\hline A & $3 \cdot 34^{*}$ & $6 \cdot 43^{* *}$ & $3 \cdot 83^{*}$ & $1 \cdot 36$ & $4 \cdot 22^{* *}$ & $0 \cdot 07$ \\
B & - & $0 \cdot 58$ & $12 \cdot 28^{* *}$ & $0 \cdot 47$ & $0 \cdot 07$ & $2 \cdot 52$ \\
D & - & - & $16 \cdot 92^{* *}$ & $2 \cdot 03$ & $0 \cdot 28$ & $5 \cdot 31^{* *}$ \\
G & - & - & - & $8 \cdot 63^{* *}$ & $13 \cdot 68^{* * *}$ & $4 \cdot 69^{* * *}$ \\
H & - & - & - & - & $0 \cdot 85$ & $0 \cdot 85$ \\
I & - & - & - & - & - & $3 \cdot 30^{*}$ \\
\hline
\end{tabular}

** For $P<0.05$. * For $0.05<P<0 \cdot 10$. 
$2000 \mathrm{bp}$ (present in all mosquitoes from all populations) hybridized most strongly, indicating a relatively higher copy number than other variants.

The results suggest that the IGS of $A$. gambiae is composed of several different elements bounded by Xho I recognition sequences. These different elements may themselves be combined into larger entities that are repeated up to several times per IGS. Three different elements of 300,400 , and $500 \mathrm{bp}$ could combine to give rise to all of the observed hybridiation fragments. For instance, the $900 \mathrm{bp}$ element could be composed of $400 \mathrm{bp}+$ $500 \mathrm{bp}$ elements while the $1400 \mathrm{bp}(900 \mathrm{bp}+$ $500 \mathrm{bp}), \quad 1700 \mathrm{bp} \quad(1400 \mathrm{bp}+300 \mathrm{bp}), \quad 2000$ $(1700 b p+300 b p)$, and $2400 b p(2000 b p+400 b p)$ fragments could be derived similarly. It is possible that the $300 \mathrm{bp}, 400 \mathrm{bp}$ and $500 \mathrm{bp}$ elements are themselves composed of the same or different repeating sequences. However, if different sequence elements are present, it should be possible to clone segments of the IGS which contain only a fraction of the repeating sequences present in the IGS. Such subclones could then hybridize to some composite Xho I-bounded fragments but not others. The IGS subclone employed in the present study obviously contains sequences homologous to all three of the smaller elements. Another IGS subclone, pAGr12D (McLain and Collins, 1989) hybridizes only to the $300 \mathrm{bp}$, $1700 \mathrm{bp}$, and $2000 \mathrm{bp}$ restriction fragments and not to the $400,500,900$ or $1400 \mathrm{bp}$ fragments. This suggests that the $300 \mathrm{bp}$ fragment is not homologous to the $400 \mathrm{bp}$ and $500 \mathrm{bp}$ fragments. Thus, the IGS contains at least two distinct sequence elements repeated in various combinations within and between genomes. These subrepeat sequence variants could be differentially homogenized in different populations.

Besides intragenomic spacer variation, much between-individual variation in the IGS was observed in some populations (e.g., site $\mathrm{H}$ ) but not in others (e.g., sites D, G and J). Little interindividual sequence variation is expected as a consequence of both recombination within the tandem arrays of rDNA genes and random segregation of chromosomes resulting from sexual reproduction (Ohta and Dover, 1984). Therefore, gene flow may be responsible for the diversity of rDNA array types within some populations.

However, the results indicate that in general gene flow is restricted between populations. For example, sites $\mathrm{G}$ and $\mathrm{H}$ are less than $10 \mathrm{~km}$ apart, but the distributions of their rDNA array types are significantly different. These differences may reflect the differential accumulation of selectively neutral spacer variants. Alternatively, spacers in different populations could be coevolving with alleles at other loci experiencing habitat imposed selection pressures (see Dover and Flavell, 1984).

If important ecological parameters varied significantly between sites then the abundance of $A$. arabiensis might vary between sites since this species prefers drier habitats while $A$. gambiae prefers more humid habitats (White, 1974). However, the relative abundances of these species varied little between field sites during the period of collection (average $=77 \cdot 1$ per cent $A$. gambiae, $\mathrm{SE}=3 \cdot 5$ per cent $)$.

Direct selection on rDNA spacer composition is probably relatively weak within populations because sexual reproduction limits the copynumber variation between individuals upon which selection must act (Ohta and Dover, 1984; Dover, 1986). The IGS appears to have a functional role that does not depend upon its base sequence (Coen and Dover, 1982; DeWinter and Moss, 1986). It is not known if or how effectively selection operates on spacer length.

The significant differences in the genotypic distributions in western Kenya indicate a subdivided population structure. This may reflect poor dispersal abilities (Jones and Gubbins, 1978) that result in reduced gene flow (see also Bull et al., 1987), and small population size that permits founder events to play an important role in interpopulation differentiation. No estimates of population size were made in the present study but collections made at the same sites from one year to the next occasionally fail to yield $A$. gambiae, suggesting substantial reductions in population size or local extinctions. This was the case with site $\mathrm{E}$ (Ahero) where no A. gambiae were collected in May, 1987 as they were the previous year.

Speciation within the A. gambiae complex may be accelerated by a subdivided population structure. Wright's (1978) shifting balance model predicts that small isolated demes will diverge rapidly through genetic drift. New adaptive genic combinations may occassionally arise because selection against intermediates has been circumvented by drift. Reduced gene flow still permits the spread of adaptive genic combinations while permitting the continued generation of other combinations (e.g., Wool, 1987; Powell, 1978; Wade and McCauley, 1984; Ringo et al., 1985).

Mosquitoes from populations of A. gambia in western and eastern Kenya differed consistently by some unshared intergenic spacer fragments, 
indicating an absence of gene flow between them. Thus, the restriction of gene flow is observed on two geographic scales. On a local scale of perhaps $10 \mathrm{~km}$ gene flow is reduced permitting local populations to diverge in the frequency of shared spacer types while on a larger scale of no more than a few hundred kilometers populations are effectively completely isolated.

Acknowledgements We thank V. Finnerty of Emory University (Atlanta, Georgia, U.S.A.) for technical advice and assistance. D. K. McLain was supported by a National Research Council Associateship during the course of this work. The research was financed by U.S. Agency for International Development PASABST-0453-P-HC-2086-02 to the Centers for Disease Control.

\section{REFERENCES}

BULL, J. J., THOMPSON, C., NG, D. AND MOORE. R. 1987. A model for natural selection of genetic migration. Am. Nat., $129,143-157$.

CHENERY, W. A. 1984. Effects of ecological changes on the malaria vectors Anopheles funestus and the Anopheles gambiae complex of mosquitoes in Accra, Ghana. J. Trop. Med. Hyg., 87, 75-81.

COEN, E. S. AND DOVER, G. A. 1982. Multiple Pol 1 initiation sites in rDNA spacers of Drosophila melanogaster. Nucl. Acids Res., 10, 7017-7026.

COEN, E. S. AND DOVER, G. A. 1983. Unequal exchanges and the coevolution of $\mathrm{X}$ and $\mathrm{Y}$ chromosomal arrays in Drosophila melanogaster. Cell, 33, 849-855.

COEN, F. S., THODAY, J. M. AND DOVER, G. 1982. Rate of turnover of structural variants in the rDNA gene family of Drosophila melanogaster. Nature, 295, 564-568.

COLlINS, F. H., MENDEZ, A., RASSMUSSEN, M. O., MEHAFFEY, P. C.., BESANSKY, N. I. AND FINNERTY, V, 1987. A ribosomal RNA probe differentiates member of species of the Anopheles gambiae complex. Am. J. Trop. Med. Hyg., 37, 37-41.

COlUzZI, M., PETRARCA, V. AND DIDECO, M. A. 1985. Chromosomal inversion intergradation and incipient speciation in Anopheles gambiae. Bull. Zool., 52, 45-63.

COluzzi, M., SABatini, A., PETRARCA, V. AND DideCO, M. A. 1977. Behavioral divergence between mosquitoes with different inversion karyotypes in polymorphic populations of the Anopheles gambiae complex. Nature, 266, 832-833.

DeWINTER, R. F. J. AND MOSS, T. 1986. Spacer promoters are essential for efficient enhancement of $X$. laevis ribosomal transcription. Cell, 44, 313-318.

DOVER, G. 1982. Molecular drive: a cohesive mode of species evolution. Nature, 299, 111-117.

DOVER, G. 1986. Molecular drive in multigene families: how biological novelties arise, spread, and are assimilated. Trends Genet., 2, 159-165.

DOVER, G. A. AND FLAVELL, R. B. 1984. Molecular coevolution: DNA divergence and the maintenance of function. Cell, $38,622-623$.

HEDRICK, P. W., GINEVAN, M. E. AND EWING, E. P. 1976. Genetic polymorphism in heterogeneous environments. Annu. Rev. Ecol. Syst., 7, 1-32.

JONES, M. D. R. AND GUBBINS, S. J. 1978. Changes in the circadian flight activity of the mosquito Anopheles gambiae in relation to insemination, feeding and oviposition. Physiol. Ent., 3, 213-220.
LEARN, G. H. JR. AND SCHAAL, B. A. 1987. Population subdivision for ribosomal repeat variants in Clematis fremontii. Evolution, 41, 433-438.

LIVAK, K. 1984. Organization and mapping of a sequence on the Drosophila melanogaster X and Y chromosomes that is transcribed during spermatogenesis. Genetics, 107, 611634.

MANIATIS, T., FRITSCH, E. F, AND SAMBROOK, J. 1982 Molecular Cloning: A Laboratory Manual. Cold Spring Harbor Laboratory.

MCLAIN, D. K. AND COLLINS, F. H. 1989. Structure of the rDNA cistron in the mosquito Anopheles gambiae and rDNA sequence variation within and between species of the $A$. gambiae complex. Heredity (in press).

NUNNEY, L. 1985. Group selection, altruism, and structureddeme models. Am. Nat., 126, 212-230.

OHTA, T. AND DOVER, G. A. 1984. The cohesive population genetics of molecular drive. Genetics, 108, 501-521.

POWELL, J. R. 1978. The founder-flush speciation theory: an experimental approach. Evolution, 32, 465-474.

RINGO, J., WOOD, D., ROCKWELL, R. AND DOWSE, H. 1985. An experiment testing two hypotheses of speciation. Am. Nat., 126, 642-661.

RISHIKESH, N., DIDECO, M. A., PETRARCHA, V. AND C:OlUZZI, M. 1985. Seasonal variations in indoor resting of Anopheles gambiae and Anopheles arabiensis in Kaduna, Nigeria. Acta Trop, 42, 165-170.

SOKAL, R. R. AND ROHLF, F. J. 1981. Biometry. Freeman, San Francisco.

Roughgarden, J. 1979. Theory of Population Genetics and Evolutionary Ecology: An Introduction. Macmillan, New York.

SOUTHERN, E. 1975. Detection of specific sequences among DNA fragments separated by gel electrophoresis. $J$. Mol. Biol., 98, 503-517.

STRACHAN, T., COEN, E. WEBB, D. AND DOVER, G. 1982. Modes and rates of change of complex DNA families of Drosophila. J. Mol. Biol., 158, 37-54.

STRACHAN, T., WEBB, D. AND DOVER, G. A. 1985. Transition stages of molecular drive in multi-copy DNA families in Drosophila. EMBO J., 4, 1701-1708.

TAUTZ, D., TAUTZ, C., WEBB, D. AND DOVER, G. A. 1987 Evolutionary divergence of promoters and spacers in the rDNA family of four Drosophila species. J. Mol. Biol., 195, 525-542.

WADE, M. I. AND McCAULEY, D. E. 1984. Group selection: the interaction of local deme size and migration in the differentiation of small populations. Evolution, 38, $1047-$ 1058 .

White. G. B. 1974. Anopheles gambiae complex and disease transmission in Africa. Trans. Roy. Soc. Trop. Med. Hyg., 68, 276-301.

WILSON, D. S. 1980. The Natural Selection of Populations and Communities. Benjamin/Cummings, Menlo Park, CA.

WILSON, D. S. 1987. Altruism in mendelian populations derived from sibling groups: the haystack model revisited. Evolution, 41, 1059-1070.

WOOL, D. 1987. Differentiation of island populations: a laboratory model. Am. Nat., 129, 188-202.

WRIGHT, S. 1940. Breeding structure of populations in relation to speciation. Am. Nat., 74, 232-248.

WRIGHT, S. 1943. Isolation by distance. Genetics, 28, 114-138. WRIGHT, S. 1978. Evolution and Genetics of Populations, Volume IV. University of Chicago Press, Chicago. 